\section{(C) OPEN ACCESS}

\title{
Volunteer activity in specialist paediatric palliative care: a national
} survey

\author{
Rachel Burbeck, Joe Low, Elizabeth L Sampson, Rosalind Scott, \\ Ruth Bravery, Bridget Candy
}

\section{ABSTRACT \\ Objective To assess the involvement of volunteers with direct patient/family contact in UK palliative care services for children and young people.}

Method Cross-sectional survey using a webbased questionnaire.

Setting UK specialist paediatric palliative care services.

Participants Volunteer managers/coordinators from all UK hospice providers $(n=37)$ and one National Health Service palliative care service involving volunteers (covering 53 services in total).

Main outcomes Service characteristics, number of volunteers, extent of volunteer involvement in care services, use of volunteers' professional skills and volunteer activities by setting.

Results A total of 21 providers covering 31 hospices/palliative care services responded (30 evaluable responses). Referral age limit was 16-19 years in 23 services and 23-35 years in seven services; three services were Hospice at Home or home care only. Per service, there was a median of 25 volunteers with direct patient/ family contact. Services providing only home care involved fewer volunteers than hospices with beds. Volunteers entirely ran some services, notably complementary therapy and pastoral/faith-based care. Complementary therapists, school teachers and spiritual care workers most commonly volunteered their professional skills. Volunteers undertook a wide range of activities including emotional support and recreational activities with children and siblings.

Conclusions This is the most detailed national survey of volunteer activity in palliative care services for children and young people to date. It highlights the range and depth of volunteers' contribution to specialist paediatric palliative care services and will help to provide a basis for future research, which could inform expansion of volunteers' roles.

\section{INTRODUCTION}

Advances in care are increasing life expectancy for children with life-limiting conditions, numbers of whom rose in England by around 30\% from over 30500 in 2000 to over 40000 in $2010 .^{1}$ Referrals to UK children's hospices have risen by $12 \%$ in the year to March 2012. ${ }^{2}$ The provision of paediatric palliative care services is relatively small, with 66 services in the UK (including National Health Service (NHS) palliative care teams) (data supplied by Help the Hospices). A survey of UK paediatric palliative care services reported 1722 volunteers involved directly with children, young people and families. They undertake a range of tasks including sibling work, complementary therapy and befriending. ${ }^{2}$ It has been estimated that volunteers reduce hospice costs by $20 \% .^{3}$

Paediatric palliative care differs from that for adults. Whereas adult services focus for a relatively short period of time (eg, a median 54 days), largely on end-of-life care following a period of progressive chronic disease, such as cancer, ${ }^{4}$ paediatric services extend over much longer periods of time, typically several years. ${ }^{5}$ Children requiring specialist palliative care not only include those with progressive diseases, such as cancer, but also life-limiting conditions, which may or may not be progressive, such as cystic fibrosis, severe cerebral palsy or Batten disease. ${ }^{6}$ These can cause severe disability resulting in susceptibility to health complications and increased likelihood of premature death. Children's palliative care aims to improve and maintain quality of life for children and their families, $^{7}$ and also takes into account a child's continuing physical, emotional and cognitive development (including 
providing education). ${ }^{8}$ This can make paediatric palliative care more complex than that for adults.

The UK coalition government's Big Society initiative gives volunteering a central role. ${ }^{9}$ Volunteers benefit children's hospices in many ways, contributing skills and experience, which enhance those of paid staff as well as bringing the local community into the hospice, which helps normalise families' experience. ${ }^{10}$ Families' social support systems often break down when faced with a child with a life-limiting condition but volunteers can help reduce isolation. ${ }^{11}$ Hospice services are greatly valued by children, young people and their families. ${ }^{12} 13$

While a concurrent survey reports the general areas in which volunteers are involved, ${ }^{2}$ it does not give further detail that would be helpful to develop services. In February 2012, we surveyed specialist paediatric palliative care services in the UK, focusing on volunteers with direct contact with children, young people and their families to ascertain this information. Our aim was to provide further detail on the activities volunteers undertake, the settings and client groups they are involved with, the extent of their contribution, such as whether they run care services, and the extent to which professionals volunteer their skills.

\section{METHOD}

We identified all UK specialist palliative care services for children and young people from the UK Together For Short Lives website (http://www. togetherforshortlives.org.uk/) and Help the Hospices. ${ }^{14}$ While we assumed that voluntarymanaged hospices involved volunteers, we contacted NHS palliative care services to check whether they involved volunteers. We did not specify an upper age limit since some hospices provide services for young adults, ${ }^{15}$ reflecting the needs of the increasing number of children surviving into and past adolescence. ${ }^{1}$

We developed a web-based 21-item questionnaire mostly of closed questions using SurveyMonkey (SurveyMonkey.com, Palo Alto, California, USA), an internet data-collection service. Questions covered service characteristics (questions 2-9), involvement and number of volunteers (questions 10-12), their role in care services by client group (affected children/ young people, siblings, parents/carers, bereaved families) $(13,15-18)$, use of professional skills (14), and activities undertaken in hospices and families' homes (19-20). The survey also asked respondents to state in a free-text box if there were other areas (not covered in the closed questions) where volunteers are deployed with direct contact with children and families (21). Volunteer managers from two hospices piloted the survey. We emailed a web link to the survey, together with supporting information, to an identified contact in each service provider, typically the volunteer manager/co-ordinator. Where organisations provided more than one hospice (or other independent service), contacts were asked to complete the survey separately for each service.

Initial data collection took place over 1 month during which we sent a reminder email in the third week. We emailed non-responders once more and telephoned on two occasions up to 1 month after the survey close date.

To check whether the data were representative of UK services, we compared responders with nonresponders on size of service and region using data supplied by Help the Hospices. Since we could not find an accepted definition for size of service in the extant literature, we used the median number of inpatient beds in all UK services with beds as a proxy for size of service for hospices with inpatient facilities (median $=8$ beds, with services without beds identified as a separate group). We did not make comparisons based on management status because only one service in our dataset was NHS-managed.

We analysed quantitative data with non-parametric statistical tests due to highly skewed distributions using SPSS V.15, with 95\% CIs calculated in Microsoft Excel. ${ }^{16}$ For categorical data, we used chi-square tests, and for scale data, Mann-Whitney U-tests, with statistically significant differences assumed at $p$ value $\leq 0.05$. We analysed free-text responses based on content. We calculated responses based on the number of services answering each question (rounded up to the nearest integer).

\section{RESULTS}

We emailed 37 hospice providers providing care in 53 voluntary-managed hospices and one NHS palliative care unit (47 in England, 3 in Scotland, 2 in Wales and 1 in Northern Ireland). A further NHS service, identified as involving volunteers, Great Ormond Street Hospital for Sick Children, is not solely a palliative care service, and so, was not surveyed.

Twenty-one hospice providers responded (57\%), covering 31 hospices/palliative care units resulting in 30 evaluable responses (57\%). There were no statistically significant differences between responders and non-responders on region or on size of service (based on number of beds).

\section{Service characteristics}

While most hospices or home care services had no lower age limit for referral, 23 (77\%; 95\% CI 59\% to $88 \%$ ) set an upper age limit of between 16 and 19 years (age at first referral). Seven services set an upper age limit between 23 and 35 years, including one service specifically for those aged over 18 years. The data were reanalysed removing cases for services with an upper age limit over 19 years. Since there were no differences in the results compared with those from the full dataset, these data are not reported. 
There were three services with no beds (10\%; 95\% CI $4 \%$ to 26\%) (2 Hospice-at-Home services and a home care service), 16 services with $1-8$ beds $(53 \%$; $95 \%$ CI $36 \%$ to $70 \%$ ), and 11 services with $>8$ beds (37\%; $95 \%$ CI $22 \%$ to $55 \%)$.

\section{Number and involvement of volunteers}

Hospice providers reported a total of 4087 volunteers (median 80 per service, IQR 22-177) (not including fundraisers, retail workers or trustees) with a total of 1106 volunteers (median 25 per service, IQR 11-77) having direct contact with children, young people and their families. Services providing only home care involved fewer volunteers (in direct contact with client groups) than hospices with beds, but differences were not statistically significant (median 13 (IQR 9-26) compared with median 30 (IQR 10-70) for hospices with 1-8 beds, and median 42 (IQR 12-85) for hospices with $>8$ beds, $\mathrm{p}$ values all $>0.05$ ).

Volunteers were most commonly involved in activities with children/young people (26 services; 87\%; 95\% CI $70 \%$ to $95 \%$ ), siblings (26 services; $87 \%$; $95 \%$ CI $70 \%$ to $95 \%$ ) and parents/carers (22 services (73\%; $95 \%$ CI $56 \%$ to $86 \%)$ ), rather than with bereaved families 20 services $(67 \%$; $95 \%$ CI $49 \%$ to $81 \%)$ or with parents referred in the antenatal period (three services (10\%; 95\% CI 4\% to $26 \%)$ ).

\section{Use of professional skills}

Volunteers using their professional skills in hospices and home care services were most commonly complementary therapists (16 services, 53\%; 95\% CI 36\% to $70 \%$ ), school teachers (five services, 17\%; 95\% CI $7 \%$ to $34 \%$ ) and spiritual care workers (five services,
17\%; 95\% CI 7\% to 34\%). There were no statistically significant differences between volunteers using their professional skills in services with 1-8 beds and those involved in services with $>8$ beds ( $\mathrm{p}$-values all $>0.05$ ).

\section{Extent of volunteer involvement in care services}

Volunteers were most commonly involved in musicbased and art-based activities, befriending and complementary therapy. They most commonly entirely ran complementary therapy services but also ran some pastoral/faith-based care services, art-based and musicbased activities, art therapy and pastoral/faith-based care in some hospices (see table 1).

\section{Volunteer activities by setting}

The most common activities undertaken by volunteers in hospices included greeting visitors to the service and undertaking recreational activities with siblings, both reported by $73 \%$ (95\% CI $56 \%$ to $86 \%$ ) of hospices. The most common activity undertaken by volunteers working in families' homes was recreational activities with siblings (reported by 23\% (95\% CI $12 \%$ to $41 \%$ ) of services) followed by recreational activities with affected children/young people, assisting with social outings and driving (all reported by $17 \%$ (95\% CI $7 \%$ to $34 \%$ ) of services). Hospices with 1-8 beds reported the widest range of activities undertaken by volunteers in families' homes compared with those with $>8$ beds or with no beds. Two respondents commented that volunteers worked in families' houses only when parents were present (see table 2).

No home-based service involved volunteers in the physical care of affected children/young people or siblings in families' homes, although seven (23\%; $95 \%$

Table 1 Number of hospices reporting care services involving volunteers but not run by them, and care services run entirely by volunteers

\begin{tabular}{|c|c|c|c|c|}
\hline & \multicolumn{4}{|c|}{$\begin{array}{l}\mathrm{N} \text { hospices reporting care services involving volunteers but not run by them ( } \mathrm{N} \text { hospices reporting } \\
\text { care services run entirely by volunteers) }\end{array}$} \\
\hline & For children & For siblings & For parents/carers & For bereaved families \\
\hline Art-based activities & $18(1)$ & 25 & 0 & 0 \\
\hline Music-based activities & $12(1)$ & 18 & 0 & 0 \\
\hline Befriending & 12 & 8 & 8 & 7 \\
\hline Complementary therapy & $13(5)$ & $9(4)$ & $12(5)$ & $0(1)$ \\
\hline Counselling & 9 & 8 & 7 & 7 \\
\hline Pastoral/faith-based care & 0 & 0 & $5(2)$ & $6(1)$ \\
\hline Hydrotherapy & 10 & 0 & 0 & 0 \\
\hline Music therapy & 9 & 0 & 0 & 0 \\
\hline Art therapy & $7(1)$ & 0 & 0 & 0 \\
\hline Gaining feedback & 0 & 0 & 4 & 3 \\
\hline Drop-in information service & 0 & 0 & 3 & 2 \\
\hline Physiotherapy & 2 & 0 & 0 & 0 \\
\hline Social work & 0 & 0 & 0 & 1 \\
\hline Occupational therapy & 1 & 0 & 0 & 0 \\
\hline
\end{tabular}


Volunteer activity

Greeting people coming into the hospice

Recreational activities with siblings in the hospice (not art/music therapy)

Serving meals and/or drinks in the hospice

Recreational activities with affected children/young adults in the hospice (not art/music therapy)

Assisting with social outings (volunteers based in the hospice)

Helping affected children/young adults use hospice facilities

Driving (volunteers based in the hospice)

Beauty therapy or hairdressing in the hospice

Giving emotional care to affected children/young adults in the hospice

Giving emotional care to families in the hospice

Running errands (eg, shopping) (volunteers based in the hospice)

Babysitting siblings in the hospice

Giving physical care to affected children/young adults (eg, turning, lifting and bathing) in the hospice

Recreational activities with siblings in families' homes

Recreational activities with affected children/young adults in families' homes

Assisting with social outings (volunteers working in families' homes)

Driving (volunteers working in families' homes)

Escorting families on hospital appointments (volunteers working in families' homes)

Giving emotional care to affected children/young adults in families' homes

Housework (volunteers based in families' homes)

Sitting with children in the last hours of life in the hospice

Taking/collecting from school (volunteers based in families' homes)

Giving emotional care to families in families' homes

Running errands (volunteers based in families' homes)

Giving advice and information to families in the hospice

Cooking (volunteers based in families' homes)

Babysitting affected children/young adults/siblings in families' homes

Sitting with children in the last hours of life in families' homes
N (\%; 95\% Cls)* hospices reporting volunteers undertake activity
$22(73 ; 56$ to 86$)$
$22(73 ; 56$ to 86$)$
$20(67 ; 49$ to 81$)$
$18(60 ; 42$ to 75$)$
$18(60 ; 42$ to 75$)$
$17(57 ; 39$ to 73$)$
$17(57 ; 39$ to 73$)$
$14(47 ; 30$ to 64$)$
$11(37 ; 22$ to 55$)$
9 (30; 17 to 48$)$
$9(30 ; 17$ to 48$)$
$9(30 ; 17$ to 48$)$
$7(23 ; 12$ to 41$)$
$7(23 ; 12$ to 41$)$
$5(17 ; 7$ to 34$)$
$5(17 ; 7$ to 34$)$
$5(17 ; 7$ to 34$)$
$4(13 ; 5$ to 30$)$
$4(13 ; 5$ to 30$)$
$4(13 ; 5$ to 30$)$
$3(10 ; 4$ to 26$)$
$3(10 ; 4$ to 26$)$
$3(10 ; 4$ to 26$)$
$3(10 ; 4$ to 26$)$
$2(7 ; 2$ to 21$)$
2 (7; 2 to 21$)$
$1(3 ; 1$ to 17$)$
1 (3; 1 to 17)

CI $12 \%$ to $41 \%$ ) involved volunteers in physical care within the hospice facility. One respondent added that their hospice was piloting this. Three services involved volunteers in sitting with children in the last hours of life within the hospice, with one involving volunteers in this way in the home.

\section{DISCUSSION}

\section{Main findings}

As far as we are aware, this is the most detailed national survey of volunteer activity in UK specialist paediatric palliative care to date. We found that volunteers were involved with all client groups, including families referred in the antenatal period and bereaved families, and in a range of activities, most commonly greeting people entering the hospice, and recreational activities with children and siblings (both in hospices and families' homes), but in some cases, in physical care and in sitting with children in the last hours of life. In a few hospices, volunteers entirely ran some care services. We found that services providing only home care involved volunteers to a lesser extent than hospices with beds.

\section{Comparison with adult services}

We have carried out a similar survey of adult services ${ }^{17}$ but no other similar survey of adult services has been undertaken. We found that the number of volunteers in children's services with direct contact with children, young people and their families is small (median 25 per service (IQR 11-70)) compared with those in adult services (median 85 per service IQR 40-150) (ref. 17-unpublished). This may not be surprising given that children's hospices are smaller than adult services (median 8 beds compared with median 15 beds), and paediatric palliative care is relatively recently developed compared with palliative care for adults. Therefore, volunteer roles are likely to be less well evolved. Also, adult hospices provide different services to those for children, for example, day care services, where it may be easier to involve a relatively large number of volunteers. We found that volunteers ran some services, notably complementary therapy 
services and pastoral/faith-based care services but also some art-based and music-based activities. This is a similar finding to our survey of adult services (ref. 17 - unpublished) and shows how dependent some services are on volunteers.

Lower numbers of volunteers in children's hospices may also reflect reluctance among providers to involve volunteers directly with children, young people and their families. To our knowledge, children's hospices generally do not struggle to attract volunteers, so the low numbers are unlikely to be because the emotional challenge of working in palliative care inhibits people from volunteering. Indeed, we found some services involving volunteers in roles with particularly emotionally challenging client groups, such as bereaved families and parents referred in the antenatal period, and in activities such as sitting with children/young people in the last hours of life. This shows the potential for involving volunteers in more emotionally demanding roles. Staff attitudes may also be an issue. While many staff are positive about volunteer involvement, some may be, at best, wary and, at worst, feel threatened by volunteers (D Pastor, personal communication, 6/12/2011). ${ }^{18}$ Both staff and parents are likely to have concerns about issues around safeguarding children and about volunteers working with children and young people with complex conditions. There is also the issue of introducing yet more people into the lives of children and young people with whom a large number of people are already involved. Further research could help address these concerns.

\section{Volunteer involvement by type and size of service}

We found that smaller hospices and those providing solely home-based care involve fewer volunteers with direct contact with children and young people, and their families, than larger hospices. This may reflect lower service user numbers (likely for those with 1-8 beds). We found that fewer providers reported activities undertaken by volunteers in families' homes compared with those reporting hospice-based volunteer activities, and also that no physical care was undertaken by volunteers in family homes, compared with seven services reporting volunteers helping with physical care in hospices. We also found smaller hospices reported the widest range of activities undertaken by volunteers in families' homes compared with larger ones. Most children and young people with lifelimiting conditions are cared for at home, ${ }^{19}$ and home-based care is particularly valued by parents 2021 and has been shown to improve parents' mental health. ${ }^{22}$ Volunteers may have the potential to enhance the role of staff teams in home care and also help reduce social isolation for families, particularly in rural areas. However, there may be reluctance among service providers and parents to involve volunteers in families' homes, for example, because of regulatory issues and issues related to confidentiality within a community setting. Again, further research is needed to explore the potential of increased volunteer involvement, and the impact of volunteers' involvement on children, young people and their families.

In addition, since many children use hospice services for a number of years, staff and volunteers have the opportunity to develop long-term relationships with them and their families. While this is likely to increase job satisfaction, it may increase personal distress when a child dies. Volunteers should be offered training and support to deal with such issues, and services should not be developed without this provision.

\section{Young people}

We found seven services with an upper age limit over 19 years. This was one more than was found by an earlier survey. ${ }^{15}$ Our survey did not ask about volunteer involvement specifically with older teenagers and young adults, so we do not know the extent of volunteering with this group. However, young people prefer facilities separate from those for children ${ }^{12}$ and can suffer significant social isolation. ${ }^{23}$ Young volunteers have an important role to play in this area ${ }^{24}$ and we are aware of successful peer befriending projects in a number of children's hospices throughout the UK, which following evaluation could be extended.

\section{Comparison with existing literature}

We found fewer volunteers with direct contact with children, young people and families than reported in another survey ${ }^{2}$ (1722 by 31 services involving volunteers compared with 1106 by 29 services in the present survey). The discrepancy may reflect the different way data were collected. Our survey was completed mostly by volunteer managers/coordinators, since our focus was on volunteers. Therefore, it may be more accurate since these respondents were the hospice team members most likely to have access to the relevant data. The other survey was completed by a 'nominated person' (it is unclear who this was) and covered all hospice activities. Also hospices that did not respond to our survey, but did respond to the other, may involve relatively large numbers of volunteers. There may have been variation among the two surveys' respondents in interpreting 'direct contact', although the other survey used similar wording to ours (CA Devanney, personal communication, 25/5/ 2012). However, the focus of our survey was on volunteer activity rather than on the numbers involved, which may be an inaccurate measure of volunteer contribution since volunteers offer differing amounts of time.

\section{Limitations}

A limitation of our survey is our response rate of $57 \%$, although not unexpected as surveys of healthcare staff often achieve relatively low response rates. ${ }^{25}$ This may be because we sent our survey to volunteer 
managers/coordinators who, although usually paid staff, often work part-time with little administrative support. Also, our survey focused on volunteers with direct contact with children, young people and families, and at least two of the hospices who did not complete our survey do not involve volunteers in this role. However, we found no difference on key characteristics between responders and non-responders, so we consider the findings of our survey representative.

\section{CONCLUSIONS}

This is the most detailed national survey of volunteer activity in specialist paediatric palliative care services to date, and shows that volunteers undertake a wide range of activities in hospices and, to a lesser extent, in families' homes. In a few hospices, volunteers entirely ran some care services. The depth of their involvement in some services shows the potential for development elsewhere. This study will help provide a basis for future research, which could inform expansion of volunteers' roles.

Acknowledgements The authors thank Dr Paula Kelly, Institute of Child Health, University College London, for reviewing the draft survey questionnaire; Wendy Bridge and Kerry Davies, Helen and Douglas House, Oxford, and Clare Bates, East Anglia Children's Hospices, Cambridge, for piloting it; Baptiste Leurent, Marie Curie Palliative Care Research Unit, UCL Mental Health Sciences Unit, University College London Medical School, for statistical advice; and Dr Louise Jones, also of Marie Curie Palliative Care Research Unit, for commenting on the draft paper.

Contributors $\mathrm{BC}$ conceived and designed the project; $\mathrm{RBu}, \mathrm{JL}$, $\mathrm{ES}, \mathrm{RS}, \mathrm{RBr}$ and $\mathrm{BC}$ contributed to the design of the survey questionnaire; $\mathrm{RBu}$ and $\mathrm{BC}$ contributed to acquisition and analysis of the data; RBu, JL, ES, RS, RBr and BC contributed to the interpretation of the data; RBu drafted the paper; and $\mathrm{RBu}, \mathrm{JL}, \mathrm{ES}, \mathrm{RS}, \mathrm{RBr}$ and $\mathrm{BC}$ contributed to critically reviewing it. RBu, JL, ES, RS, $\mathrm{RBr}$ and $\mathrm{BC}$ approved the final version.

Funding This study was funded by the Dimbleby Marie Curie Cancer Care Research Fund (grant reference DCMC-RF-11-02).

\section{Competing interests None.}

Ethics approval Ethical approval for the study was obtained from University College London Research Ethics Committee (approval number 3077/001 25 January 2012).

Provenance and peer review Not commissioned; externally peer reviewed.

Open Access This is an Open Access article distributed in accordance with the Creative Commons Attribution Non Commercial (CC BY-NC 3.0) license, which permits others to distribute, remix, adapt, build upon this work noncommercially, and license their derivative works on different terms, provided the original work is properly cited and the use is non-commercial. See: http://creativecommons.org/licenses/by$\mathrm{nc} / 3.0 /$

\section{REFERENCES}

1 Fraser LK, Miller M, Hain R, et al. Rising national prevalence of life-limiting conditions in children in England. Pediatrics 2012;129:e923-9.

2 Devanney C, Bradley S. Together for Short Lives. Count Me In: Children's Hospice Service Provision 2011/12. Durham University School of Applied Social Sciences and Together for Short Lives, 2012.
3 Help the Hospices. Volunteer Value. A pilot survey of UK hospices. Help the Hospices, 2006.

4 Good PD, Cavenagh J, Ravenscroft PJ. Survival after enrollment in an Australian palliative care program. J Pain Symptom Manag 2004;27:310-5.

5 Feudtner C, Kang TI, Hexem KR, et al. Pediatric palliative care patients: A prospective multicenter cohort Study. Pediatrics 2011;127:1094-101.

6 Together for Short Lives http://www.act.org.uk/page.asp? section $=164 \&$ sectionTitle $=$ Categories + and + life $\% 2$ Dlimiting + and + life $\% 2$ Dthreatening + conditions (accessed 23 Aug 2012).

7 World Health Organisation. WHO definition of palliative care for children. http:/www.who.int/cancer/palliative/definition/en/ (accessed 23 Aug 2012).

8 Together for Short Lives http://www.act.org.uk/page.asp? section $=162 \&$ sectionTitle $=$ Differences + between + children $\%$ $27 \mathrm{~s}+$ and +adult $\% 27 \mathrm{~s}+$ palliative + care (accessed $23 \mathrm{Jul} 2012$ ).

9 Cabinet Office. Big Society strategy for charities, voluntary groups and social enterprises. 2010. http://www.cabinetoffice. gov.uk/newsroom/news_releases/2010/101014-big-societystrategy.aspx (accessed 2 May 2012).

10 Scott R. Volunteers in a Children's Hospice. In: Scott R, Howlett $\mathrm{S}$, et al. eds. Volunteers in hospice and palliative care: A resource for voluntary services managers. 2 nd edn. Oxford: Oxford University Press, 2009:145-60.

11 Brenner P. Unpaid staff the volunteer component. In: Armstrong-Dailey A, Zarbock S.eds Hospice care for children. 2nd edn. New York: Oxford University Press, 2001.

12 Kirk S, Pritchard E. An exploration of parents' and young people's perspectives of hospice support. Child Care Health Dev 2012;38:32-40.

13 Swallow V, Forrester T, MacFadyen A. Teenagers' and parents' views on a short-break service for children with life-limiting conditions: a qualitative study. Palliat Med 2011; 26:257-67.

14 Help the Hospices. Hospice and palliative care directory. United Kingdom and Ireland, 2009-2010. Help the Hospices, 2009.

15 Mash E, Lloyd-Williams M. A survey of the services provided by children's hospices in the United Kingdom 2006. Support Care Cancer 2006;14:1169-72.

16 Herbert R. Confidence interval calculator for NNTs and much more. http://www.pedro.org.au/wp-content/uploads/ CIcalculator.xls (accessed 11 Feb 2013).

17 Burbeck R, Low J, Sampson EL, et al. Volunteers in specialist palliative care: A survey of adult services in the UK. J Pain Symptom Manag. In press.

18 Field-Richards S E, Arthur A. Negotiating the boundary between paid and unpaid hospice workers: A q study of how hospice volunteers understand their work. Am J Hosp Palliat Med 2012;29:627-31.

19 Ling J. Respite support for children with a life-limiting condition and their parents: a literature review. Int J Palliat Nurs 2012;18:129-34.

20 Redmond B, Richardson V. Just getting on with it: exploring the service needs of mothers who care for young children with severe/profound and life-threatening intellectual disability. J Appl Res Intellect Disabil 2003;3:205-18.

21 Whitton C, Williams C, Wright B, et al. The role of evaluation in the development of a service for children with life-limiting conditions in the community. Child Care Hlth Dev 2008:34:576-83. 
22 Shu BC, Lung FW, Huang C. The mental health of family caregivers with intellectually disabled children who receive a home care program. I Intell Disabil Res 2002; 46:257-63.

23 Marsh S, Cameron M, Duggan M, et al. Young people with life-limiting conditions: transition to adulthood. Phase 1 report for Marie Curie Cancer Care. 2011. http://www.mariecurie. org.uk/Documents/HEALTHCARE-PROFESSIONALS/
Innovation/teenagers-transition/young-people-transition-pswexec-summary.pdf (accessed 6 Jun 2012).

24 Scott R, Burgin D. Volunteering for the future: the impact on young volunteers on volunteering in paediatric palliative care. $J$ Volunt Admin 2004:22:21-5.

25 Cook JV, Dickinson HO, Eccles MP. Response rates in postal surveys of healthcare professionals between 1996 and 2005: An observational study. BMC Health Services Research 2009;9:160. 